\title{
Percutaneous Aspiration-Injection-Reaspiration of Hepatic Cystic Echinococcosis
}

\begin{abstract}
ADELINA PAPANCEA ${ }^{1}$, STEFAN OCTAVIAN GEORGESCU ${ }^{1}$, DAN VINTILA ${ }^{1}$, CORINA URSULESCU LUPASCU ${ }^{2}$, DANIEL TIMOFTE ${ }^{1 *}$, VASILE FOTEA², FLORIN PETRARIU33, BOGDAN MIHNEA CIUNTU1*

${ }^{1}$ Grigore T. Popa University of Medicine and Pharmacy, Faculty of General Medicine, Surgery Department, 16 Universitatii, Str., 700115 , lasi, Romania

${ }^{2}$ Grigore T. Popa University of Medicine and Pharmacy, Faculty of General Medicine, I Medical Department, 16 Universitatii, Str., 700115, lasi, Romania

${ }^{3}$ Grigore T. Popa University of Medicine and Pharmacy, Faculty of General Medicine,Department of Preventive Medicine and Interdisciplinarity, 6 Universitatii, Str., 700115, lasi, Romania

Human echinococcosis is a zoonotic infection caused by larval forms (metacestodes) of the tapeworm of the genus echinococcus found in the small intestines of carnivores. Humans are only incidentally infected. The liver is the most frequent site for the cystic lesions seen in hydatid disease, followed by the lung, the brain, and other visceral. Surgery is the recommended treatment for hepatic hydatid cysts. However, drug therapy and percutaneousdrainage have recently been introduced as alternative treatments. We present the case of a 68 year old female pacient that admitted in our clinic for pain in the superior abdominal region. The ecography performed revealed a large cystic formation about $700 \mathrm{~mL}$ with a diameter of $10 \mathrm{~cm}$ in the right lobe of the liver. We performed a Percutaneous Aspiration-Injection-Reaspiration Drainage (PAIR) under Albendazol treatment before and after the procedure without any incidents. The histopathological examination concluded the diagnosis of hydatid hepatic cyst. Percutaneous drainage is minimally invasive and very effective in the treatment of hepatic hydatidosis. Percutaneous aspiration of a documented or suspected hydatid cyst was long considered to be contraindicated to avoid the risk of leakage of cyst contents, which can lead to anaphylaxis and seeding of intraperitoneal structures. In the our case report the hydatid hepatic cyst was a large univezicular cyst, with a approachable localization in the liver, on a pacient without any other medical problems that was suitable for PAIR, and after the procedure we didn'tidentified any of the complication reported in literature. The effectiveness of PAIR method allowed a short period of hospitalization with ambulatory follow up with benefits on the both sides, the pacientsocial integration and medical system economy.
\end{abstract}

Keywords: Hydatid Hepatic Cyst, Echinococcusgranulosus, Percutaneous Aspiration-Injection-Reaspiration Drainage, Albendazole

Human echinococcosis is a zoonotic infection caused by larval forms (metacestodes) of the tapeworm of the genus echinococcus found in the small intestines of carnivores. Human infection is acquired from ingestion of the parasite eggs from infected animals.

Echinococcusgranulosus causes cystic echinococcosisin humans, a condition that is found throughout the world [1]. Hippocrates recognized hydatid disease 2000 years ago. The disease remains endemic in sheep raising areas of the world, including Africa, the Mediterranean region of Europe, the Middle East, Asia, South America, Australia, and New Zealand. Dogs are the definitive hosts for $E$. granulosus, and sheep are the major intermediate host. Yaks, goats, and camels are other relevant intermediate hosts. Humans are only incidentally infected. The liver is the most frequent site for the cystic lesions seen in hydatid disease, followed by the lung, the brain, and other visceral [2]. Surgery is the recommended treatmentfor hepatic hydatid cysts. However, drug therapy and percutaneousdrainage have recently been introduced as alternative treatments. Two benzimidazoles (mebendazoleandalbendazole) have scolicidal activity but are clinically effective in less than 30 percent ofpatients with hepatic hydatidosis.Percutaneous drainage is minimally invasive and very effective inthe treatment of hepatic hydatidosis.Studies of large numbers of patients followed for up to five years have shown that the risk of anaphylaxis is negligible, and regrowth of cysts does not occur [3].

\footnotetext{
*email: dantimofte@yahoo.com; bogdanmciuntu@yahoo.com
}

\section{Experimental part}

We present the case of a 68 year old female pacient that admitted in our clinic for pain in the superior abdominal region. The biochemical test was normal, except the $\lg E$ for the hydatid cyst was $768 \mathrm{U} / \mathrm{mL}$ with the reference value of $0-87 \mathrm{U} / \mathrm{mL}$. The ecography performed revealed in the segment IV and VIIla large cystic formationabout $700 \mathrm{~mL}$ with a diameter of $10 \mathrm{~cm}$ in the right lobe ofthe liver with aspect of hepatic hydatid cyst (Fig. 1).

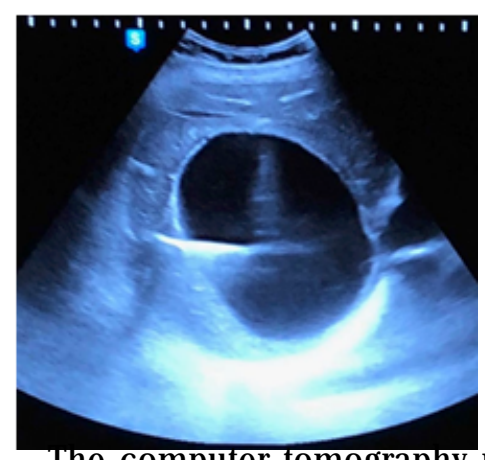

Fig. 1. Large cystic formation in the right lobe of the liver

The computer tomography revealed an ovoid lowdensity mass in the right lobe of the liver. There is no definite calcification of the pericyst (Fig. 2).

The pacient was on Albendazole $800 \mathrm{mg} /$ day for 22 days with a pause from the treatment for 14 days before the PAIR procedure.We performed a Percutaneous AspirationInjection-Reaspiration Drainage (PAIR). The percutaneous puncture was done under local anesthesia using a CHIBA 

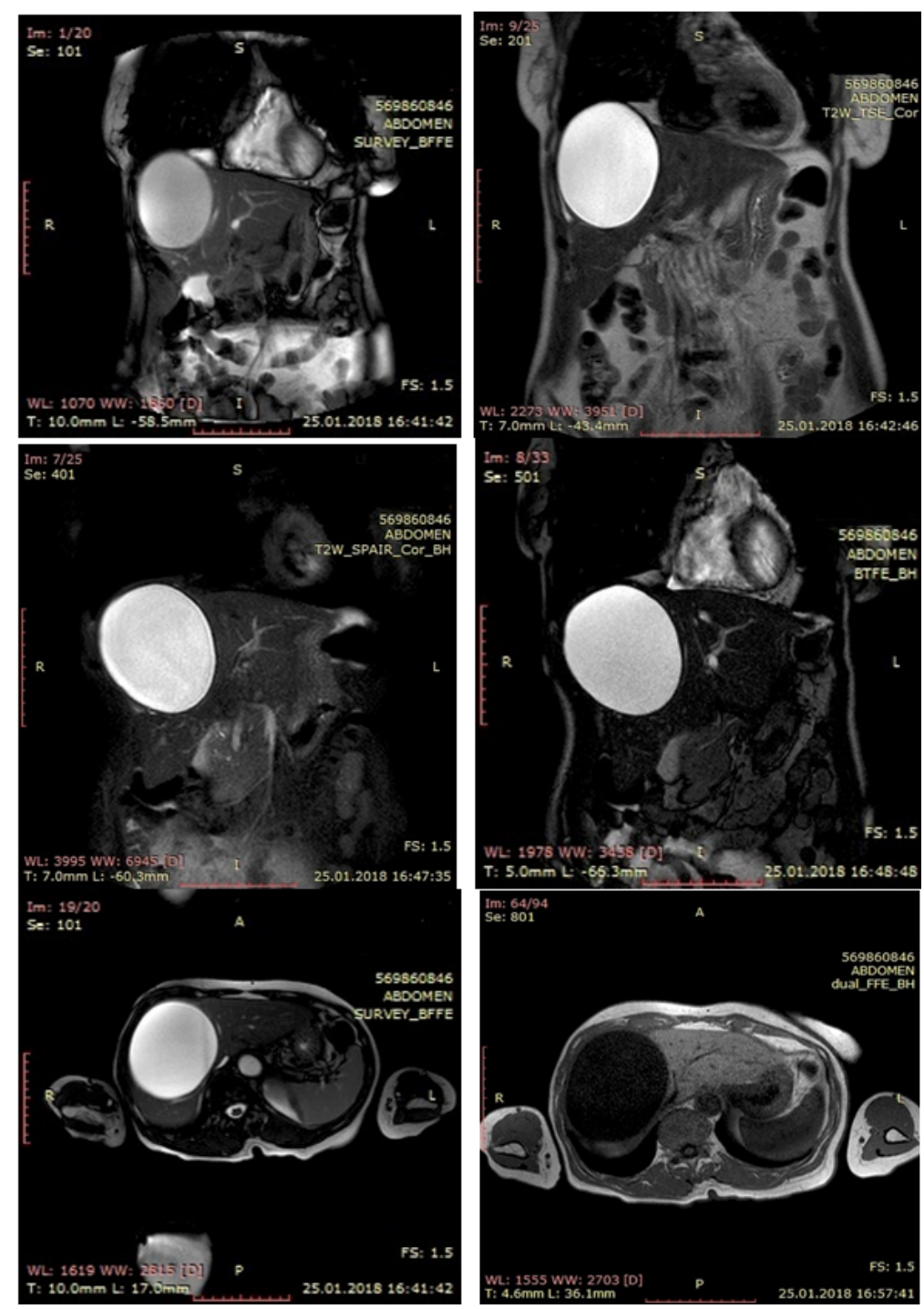

needle of 18 Gauge. We prelevated a sample of fluid for the histopathological examination. We drained in a closesistem the cystic fluid and we insert in the cystic cavity $300 \mathrm{~mL}$ of hypertonic serum $20 \%$ for about 20 min, after we aspirated the fluid with membrane fragments, as well a sample for the post procedure (Fig. 3).

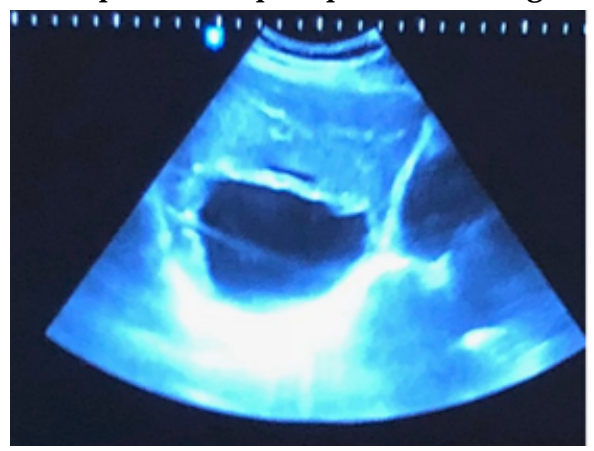

Fig. 3.The ecographyc image after the instillation of the hypertonic serum

After the drainage of the cyst the remaining cavity had a diameter about $2 \mathrm{~cm}$. On the 3th'day post procedure we did a check upecography that revealed a formation with fluid inside in the segment VII of the liver with the diameter of $88 / 63 / 77 \mathrm{~mm}$ with folted membranes inside.

The histopathological examination concluded that the sample had the aspect of hydatid hepatic cyst. The pacient was released from our clinic in the $3^{\prime}$ th day after the PAIR with the Abendazole treatment $800 \mathrm{mg}$ per day for 2 weeks with a favorable evolution after the procedure.
Fig. 2.0void low-density mass in the right lobe of the liver

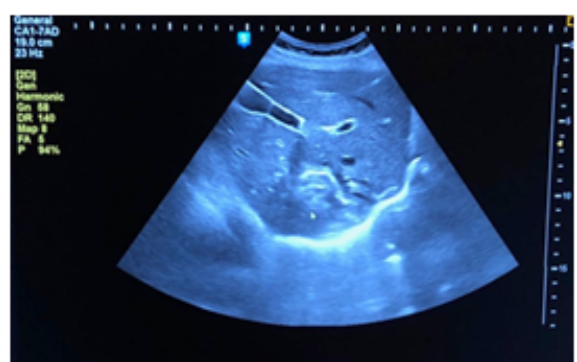

Fig 4.The formation in the segment VII of the liver with folted membranes inside

\section{Results and discussions}

Human echinococcosis is a zoonotic infection caused by larval forms (metacestodes) of the tapeworm of the genus echinococcus found in the small intestines of carnivores. Human infection is acquiredfrom ingestion of the parasite eggs from infected animals. Echinococcusgranulosus causes cystic echinococcosis in humans, a condition that is found throughout the world [1]. Hippocrates recognized hydatid disease 2000 years ago. The disease remains endemic in sheepraising areas of the world, including Africa, the Mediterranean region of Europe, the Middle East, Asia, South America, Australia, and New Zealand. Dogs are the definitive hosts for $E$. granulosus,and sheep are the major intermediate host. Yaks, goats, and camels are other relevant intermediate hosts. Humans are only incidentally infected. The liver is the most frequent site for the cystic lesions seen in hydatid disease, followed by the lung, the brain, and other viscera [2]. Surgery is the recommended treatment for hepatichydatid cysts. However, drug therapy and 
percutaneous drainage have recently been introduced asalternative treatments.Twobenzimidazoles (Mebendazole and Albendazole) have scolicidal activity butare clinicallyeffective in less than 30 percent of patients with hepatic hydatidosis.

Percutaneous drainage is minimally invasive and very effective in the treatment of hepatic hydatidosis. Studies oflarge numbers of patients followed for up to five years have shown that the risk of anaphylaxis is negligible, and regrowth of cysts does not occur [3].

Percutaneous aspiration of a documented or suspected hydatid cyst was long considered to be contraindicated to avoid the risk of leakage of cyst contents, which can lead to anaphylaxis and seeding of intraperitoneal structures. Since the advent of drug therapy effective against Echinococcusspecies, many health care centers now advocate an approach consisting of pre- and postoperative chemotherapy with Albendazole or Mebendazole, combined with percutaneous drainage (consisting of puncture, aspiration, injection, and reaspiration [PAIR]) of hepatic hydatid cysts [4-8].

The goals of surgery in hydatid disease are to inactivate the cestode parasites, evacuate the cyst cavity, remove the germinal layer, and obliterate the residual cavity. PAIR treatment satisfies all of these goals but substitutes germinal membrane sclerosing and separation by means of scolicides for surgical removal. PAIR (puncture, aspiration, injection, and reaspiration) is a percutaneous treatment technique for hydatid disease. This technique was proposed in 1986 by the Tunisian team that first used it in a prospective study [9]. In this minimally invasive method, a needle is introduced into the cyst under ultrasound guidance. Since that time, its use in the treatment of hydatid cysts has been somewhat controversial [9-13]. However, as this technique has become more common and its safety and efficacy have been reported in the literature [14-19], it has been increasingly accepted as a treatment option for hydatid disease. The World Health Organization currently supports PAIR as an effective alternative to surgery, although its use is limited. The World Health Organization guidelines for indications and contraindications of PAIR are as follows [17]:

1. Indications for PAIR

-Nonechoic lesion greater than or equal to $5 \mathrm{~cm}$ in diameter

-Cysts with daughter cysts and/or with membrane detachment

-Multiple cysts if accessible to puncture

-Infected cysts

-Patients who refuse surgery.

-Patients who relapse after surgery.

-Patients in whom surgery is contraindicated

-130 Abdominal Surgery

-Patients who fail to respond to chemotherapy alone

-Children over 3 years.

-Pregnant women

2. Contraindications for PAIR

-Non cooperative patients

-Inaccessible or risky location of the liver cyst

-Cyst in spine, brain, and/or heart

-Inactive or calcified lesion

-Cyst communicating with the biliary tree

-Patients should be followed clinically after PAIR treatment. [17]

Recurrence is increased in more complicated cysts, including those with multiple daughter cysts. PAIR should only be performed in highly specialized centers with appropriately trained and experienced staff. In addition, an anaesthesiologist should be present for monitoring and treatment in case of anaphylactic shock. Surgeons should be notified immediately in case of complication [10-20].

In our case the PAIR procedure was done with the help of a surgeon and an operating room was ready in case of post procedure complications. Punctures of hydatid cysts have been discouraged in the past due to the potential risk of Anaphylactic shock and peritoneal dissemination.

However, in the recent years percutaneous drainage has been used successfully to treat the hepatic hydatid cysts. Khuroo et al [13] reported 88\% disappearance of cysts with percutaneous drainage which was preceded by Albendazole therapy ( $10 \mathrm{mg} / \mathrm{kg}$ body weight) for 8 weeks. In his study, he showed that the efficacy of percutaneous drainage is similar to that of standard treatment with cystectomy, in terms of reducing the size of the cyst and causing its disappearance over a period of up to two years.

The advantages of percutaneous drainage include a shorter hospital stay and a lower complication rate.Percutaneous treatment of LHCs introduced in the mid1980s has become an attractive alternative to surgery and medical management [21]. The first percutaneous treatment used was to puncture the cyst, aspirate cyst fluid, inject a scolicidal agent (e.g., hypertonic saline, 95\% ethanol, albendazole or betadine), and re-aspirate the cyst content (PAIR) [22]. Khuroo and others found PAIR under ultrasonography or tomograph guidance, combined with peri intervention albenzimidazole derivatives to be as effective as open surgical drainage with fewer complications and less cost [23]. Yagci et al from Turkey reported a single-center experience comparing surgery, laparoscopic surgery, and percutaneous treatments in 355 patients of LHCs over a period of 10 years and concluded that PAIR is an effective and safe option [24]. Giorgio and others and Kabaalioglu and others reported repeated failures of PAIR in multivesiculatedcysts [25].

These findings prompted most clinicians to use PAIR exclusively for unilocular cysts, with or without detached endocysts. Other percutaneous techniques are generally reserved for cysts that are difficult to drain or tend to relapse after PAIR (multivesiculated cysts or cysts with predominantly solid content and daughter cysts). Percutaneous evacuation (PEVAC), modified catheterization technique (MoCaT), and dilatable multifunction trocar (DMFT) are some of the devices used for aspiration of the solid content of the LHCs, the germinal and the laminated layer. A much less well-evaluated percutaneous technique to destroy the germinal layer by means of high temperature is radiofrequency $(\mathrm{RF})$ thermal ablation.

Preliminary reports are rather disappointing because nearly all the cysts treated relapsed after a few months [26]. The major risks of percutaneous techniques are anaphylactic shock, secondary echinococcosis caused by spillage of cystic fluid, and chemical cholangitis caused by contact of the scolicidal agent with the biliary tree. Such major complications are reported to be only $0.38 \%$ and secondary echinococcosis as a result of spillage of fluid is reported to tune of $1.27 \%$ in the literature available. It is unclear whether this is because of spillage-free puncture, Albendazole prophylaxis, or underreporting because of incomplete follow-up regarding length and imaging techniques used. Safety and efficacy of percutaneous treatments is also related to the anatomical site of the cyst [27].

Percutaneous drainage of liver hydatid cysts has been contraindicated for many years as a result of the potential risk of anaphylactic shock and spillage of the parasite, 
resulting in dissemination and peritoneal implantation. Both of these complications are extremely rare and should not be considered as characteristic contraindications [28]. The development of fine needles and catheters in combination with the advances in imaging techniques, by which the right intercostal intrahepatic approach is selected, minimized the risk of anaphylactic shock orspillage [29].

The overall complication rates in percutaneous drainage range from $15-40 \%$. In previously treated surgical cases, the incidence of complications after percutaneous drainage is quite higher. Major complications, such as anaphylactic shock, are rare $(0.1-0.2 \%)$. Minor complications (urticaria, itching, hypotension, fever, infection, fistula and rupture in biliary system) range from $10-30 \%$ [30]. Cyst-biliary communications (biliary rupture and fistula formation), developing after PAIR and caused by cyst decompression, can usually be handled endoscopically [31] or, in case of inability or recurrence, by cyanoacrylate infusion [32]. Cholangiography or endoscopic retrograde cholangiopancreatography is recommended before any attempt for percutaneous drainage to inject contrast material to make any communication visible The overall mortality ranges from $0.9-2.5 \%$ among several studies of the past, a rate that has been lowered to $0.1 \%$ in a recent meta-analysis [31]. Mortality factors are associated with perioperative complications, patient's age, and infection of the remaining cyst cavity. Hospitalization period is approximately 1 day, whereas in complicated cases it might range from 17-20 days [33].

Percutaneous drainage seems to be the ideal therapy for liver hydatid disease because it combines cure with low morbidity [34-36].

In a recently published meta-analysis comparing surgery with PAIR in 1721 patients, the latter has been shown to have fewer major ( $25.1 \%$ vs $7.9 \%$ ) and minor (33.0\% vs $13.1 \%$ ) complications and fewer recurrence rates $(6.3 \%$ vs $1.6 \%)$ [31]. This could be also correlated in some small degree with others results, including the latest interest of our group in a multidisciplinary approach on laparoscopic surgery and metabolic dysfunctions associated deficits [37-42], especially considering that percutaneous aspiration-injection-reaspiration of hepatic cystic echinococcosis can be indeed associated with a multitude of other manifestations [43].

The efficacy of percutaneous treatment has also been documented in pediatric cases, because ithas been proved that the long-term results of the method are in accordance with the results of adults [44]. Where indicated, percutaneous drainage is the most effective and reliable minimally invasive interventional procedure, which is associated with low mortality, morbidity, and recurrence and short hospitalization [45].

\section{Conclusions}

In our case report the hydatid hepatic cyst was a large univezicular cyst, with a approachable localization in the liver, on a pacient without any other medical problems that was suitable for PAIR, and after the procedure we didn't identified any of the complication reported in literature.

The effectiveness of PAIR method allowed a shortperiod of hospitalization with ambulatory follow up with benefits on the both sides, the pacient social integration and hospital economy.

\section{References}

1.MILICEVIC, M., Hydatid disease. In: Blumgart LH, ed. Surgery of the liver and biliary tract. 2nd ed. Vol. 2. Edinburgh, Scotland: Churchill Livingstone, 1994, p. 1121.

2.SMEGO, R.A., BHATTI, S., KHALIQ, A.A., BEG, M.A., Clinical Infectious Diseases, 37, no. 8, 2003, p. 1073. DOI: 10.1086/378275.

3.MOHAMMAD, S.K., NAZIRA, W., GULJ AV, D., BASHIA, K., GHULAMN, Y, ALTAFH, S, SAMOOONG, J., N. Engl. J. Med., 337, 1997, p. 881.

4.VUITTON, D.A., MESLIN, F., MACPHERSON, C., BRUNETTI, E., FILICE, C., (eds.), PAIR: An Option for the Treatment of Cystic Echinococcosis, World Health Organization Informal Working Group on Echinococcosis, Bull World Health Organ, 2002.

5.ECKERT, J., (ed.), OIE Manual on Echinococcosis in Humans and Animals. Geneva: HO/OIE, 2001.

6. MUELLER, P.R., DAWSON, S.L., FERRUCCI, J.T., NARDI, G.L., Radiology, 155, 1985, p. 627.

7. BRET, P.M., FOND, A., BRETAGNOLLE. M., et al., Radiology, 168, 1988, p. 617.

8.KHUROO, M.S., ZARGAR, S.A., MAHAJAN, R., Radiology, 180, 1991, p. 141.

9.BEN AMOR, N., GARGOURI, M., GHARBI, H.A., GOLVAN, Y.J ., AYACHI, K., KCHOUCK, H., Ann. Parasitol. Hum. Comp., 61, 1986, p. 689.

10.PALEZ, V., KUGLER, C., CORREA, D., CARPIO, M.D., ActaTropica., 75, 2000, p. 197.

11.YAGHAN, R., HEIS, H., BANI-HANI, K., et al., Am. J. Surg., 187, 2004, p. 533.

12.GIORGIO, A., TARANTINO, L., FRANCICA, G., et al., Radiology, 184, 1992, p. 705.

13.KHUROO, M.S., WANI, N.A., JAVID, G., et al., N. Engl. J. Med., 337, 1997, p. 881.

14.KABAALIOGLU, A., CEKEN, K., ALIMOGLU, E., APAYDIN, A., Eur. J. Radiol., 59, 2006, p. 65.

15.GIORGIO, A., Di SARNO, A., De STEFANO, G., LIORRENUNZIA, G., UMBERTO SCOGNAMIGLIO, F., GIORGIO, V., AJR, . 193, 2009, p. 186. 16.PELAEZ, V., KUGLER, C., CORREA, D., DEL CARPIO, M., GUANGIROLI, M., MOLINA, J., MARCOS, B., LOPEZ, E., ActaTropica, 75, 2000, p. 197.

17. *** PAIR: Puncture, Aspiration, Injection, Re-Aspiration- An option for the treatment of Cystic Echinococcosis World Health Organization. WHO/CDS/CSR/APH/2001.6

18.SAKHRI, J., BEN ALI, A., J. Chir., 141, no. 6, 2004, p. 381.

19.BEN AMOR, N., GARGOURI, M., GHARBI, H.A., GOLVAN, Y.J ., AYACHI, K., KCHOUK, K.H., Ann. Parasitol. Hum. Comp., 61, 1986, p. 689.

20.BEN AMOR, N., GARGOURI, M., GHARBI, H.A., GOLVAN, Y.J ., AYACHI, K., KCHOUK, K.H., Digestive Diseases and Sciences, 39, 1994, p. 1576.

21.MUELLER, P.R., DAWSON, S.L., FERRUCCI. J.T. J r, NARDI, G.L., Radiology, 155, 1985, p. 627.

22.FILICE, C., PIROLA, F., BRUNETTI, E., DUGHETTI, S., STROSSELLI, M., FOGLIENI, C.S., Gastroenterology, 98, 1990, p. 1366.

23.KHUROO, M.S., DAR, M.Y., YATTOO, G.N., et al., Gastroenterology, 104, 1993, p. 1452.

24.YAGCI, G., USTUNSOZ, B., KAYMAKCIOGLU, N., et al., World J. Surg., 29, 2005, p. 1670.

25.KABAALIOGLU, A., CEKEN, K., ALIMOGLU, E., APAYDIN, A., Eur. J. Radiol., 59, 2006, p. 65.

26.BRUNETTI, E., GULIZIA, R., GARLASCHELLI, A., FILICE, C., Am. J. Trop. Med. Hyg., 71, 2004, p. 182.

27.YAGHAN, R., HEIS, H., BANI-HANI, K., et al., Am. J. Surg., 187, 2004, p. 533.

28.AKHAN, O., OZMEN, M.N., DINCER, A., et al., Radiology, 198, 1996, p. 259.

29.MEN, S., HEKIMOGLOU, B., YECESOV, C., et al., N. Engl. J. Med., 337, 1997, p. 881

30.AKHAN, O., BILGIC, S., AKATA, D., et al., Abdom. Imaging., 23, 1998, p. 209.

31.SMEGO, R.A., SEBANEGO, P., Int. J. Infect. Dis., 9, 2005, p. 69. 
32.KURAN, S., DISIBEYAZ, S., PARLAK, E., et al., Dig. Dis. Sci., 1, 2006, p. 18.

33.ORMECI, N., SOUKAN, I., BEKTAS, A., et al., Am. J. Gastroeneterol., 96, 2001, p. 2225.

34.TARANTINO, G., DESTEFANO, G., MARINIELLO, F., et al., J. Ultrasound Med., 20: 2001729- 738.

35.YAGCI, G.Y., USTUNSOZ, B., KAYMAKCIOGLOU, N., et al. World J. Surg., 29, 2005, p. 1670.

36.KOHLHAUFL, M., Ultraschall. Med., 16, 1995, p. 218.

37.NEAGOE, R.M., CVASCIUC, I.T., MURESAN, M., SALA, D.T., Acta Endo (Buc), 13, no. 4, 2017, p. 467.

38. CIOBICA, A., PADURARIU, M., CIOBICA, A., et al., International J ournal of Geriatric Psychiatry, 32, no. 1, 2017, p. 116.

39.0CHIUZ, L., GRIGORAS, C., POPA, M., et al. Molecules, 21, no. 7, 2016, p. 858.
40.ARCAN, O., BILD, W., CIOBICA, A., et al., Romanian Biotechnological Letters, 19, no. 5, 2014, p. 9763.

41.GRADINARU, I., TIMOFTE, D., VASINCU, D., et al., Mat. Plast., 51, no. 3, 2014, p. 230.

42.NEAGOE, R.M., MURESAN, M., BANCU, S., et al., Obesity Surg., 27, no. 4, 2016, p. 983.

43.SMEGO, R.A., Jr, BHATTI, S., KHALIQ, A.A., BEG, M.A., Clin. Infect. Dis., 37, no. 8, 2003, p. 1073.

44.GOKTAY, A.Y., SECIL, M., GULCU, A., et al., J. VascInterv. Radiol., 16, 2005, p. 831.

45.AKHAN, O., OZMEN, M.N., Eur. J. Radiol., 32, 1999, p. 76.

Manuscript received: 28.06.2019 